устройства. - Режим доступа: http:// docs.cntd.ru/.

5. СП 280.1325800.2016. Свод правил. Системы подачи воздуха на горение и удаления продуктов сгорания для теплогенераторов на газовом топливе. Правила проектирования и устройства. - Режим доступа: http:// docs.cntd.ru/.

Жила Виктор Андреевич, канд. техн. наук, доцент кафедры «Теплогазоснабжение и вентиляцуия», Московский государственный строительный университет. Россия.

Куркова Ксения Юрьевна, студентка, Московский государственный строительный университет. Россия.

129337, г. Москва, Ярославское шоссе, 26.

Тел.: (495) 781-80-07.

Ключевые слова: индивидуальные автоматизированные теплогенераторы; автоматика безопасности; забор воздуха для горения; дымоходы для удаления продуктов сгорания; внутреннее газоснабжение.

\title{
FEATURES OF APARTMENT-BY-APARTMENT HEATING SYSTEMS
}

Zhila Viktor Andreevich, Candidate of Technical Sciences, Associate Professor of the chair "Heat and gas Supply and Vertilation”, Moscow State University of Civil Engineering. Russia.

Kurkova Kseniya Yuryevna, Student, Moscow State University of Civil Engineering. Russia.

Keywords: individual automated heat generators; automation of safety; intake of combustion air; chimneys for the removal of combustion products; internal gas supply.

It is noted that at present the apartment-by-apartment heating systems have become widespread. At the same time, heat sources are automated boilers with closed and open combustion chambers. It is mentioned that all boilers are equipped with safety automation, flue gas discharge is provided.

\section{РАЗРАБОТКА И ОЦЕНКА КАЧЕСТВЕННЫХ ПОКАЗАТЕЛЕЙ МОЛОЧНОГО МУССА С ИСПОЛЬЗОВАНИЕМ НАПОЛНИТЕЛЯ - РЯБИНЫ ОБЫКНОВЕННОЙ}

\author{
МЕРКУЛОВА Анастасия Андреевна, Орловский государственный аграрный университет \\ имени Н.В. Парахина \\ РОДИНА Наталья Дмитриевна, Орловский государственный аграрный университет имени \\ Н.В. Парахина \\ СЕРГЕЕВА Екатерина Юрьевна, Орловский государственный аграрный университет имени \\ Н.В. Парахина
}

МАМАЕВ Андрей Валентинович, Орловский государственный аграрный университет имени H.В. Парахина

Цикин Сергей Сергеевич, Орловский государственный аграрный университет имени H.В. Парахина

Авторами была разработана рецептура нескольких образцов молочного мусса с использованием наполнителя-джема из ягод рябины обыкновенной. Все образцы исследовалисъ по органолептическим и физико-химическим показателям, наблюдалось нарастание кислотности, была произведена балльная оценка показателей молочного мусса с джемом из ягод рябины обыкновенной.

Введение. Молочная промышленность России является важной сферой деятельности, которая концентрируется на производстве продуктов, предназначенных для потребления россиянами, а также некоторая часть продукции поступает даже в другие страны в качестве экспорта. Рынок молочной продукции - один из важнейших продовольственных рынков, который динамично развивается как в Российской Федерации, так и в ее регионах. Продукция молочной промышленности востребована практически всем населением страны. Современный рынок продуктов рационального питания на $65 \%$ состоит из молочных продуктов [4].

Благодаря популяризации здорового образа жизни и правильного питания, а также росту доходов населения, рынок молочных продук- тов ежегодно увеличивается как с точки зрения объемов продаж, так и расширения ассортимента предлагаемой продукции.

На отечественном рынке молочные десерты занимают особенный сегмент. Сладкие молочные продукты воспринимаются российским потребителем как более выигрышная альтернатива другим видам десертов, они отлично вписываются в концепцию здорового образа жизни и правильного питания [3].

Молочные продукты играют немаловажную роль в рационе питания людей различных возрастных групп, поскольку обеспечивают организм энергетическими составляющими и биологически активными веществами, такими как кальций, фосфор, белок, витаминами $\mathrm{A}, \mathrm{B}_{2}$, $\mathrm{B}_{12}$. Молочный белок, жир и сахар легко усвояе- 
мы, благоприятно влияют на пищеварительные процессы.

По мнению специалистов, рынок молочных десертов считается одним из самых динамично развивающихся и маржинальных. Их высокая востребованность приводит к расширению ассортимента в данной группе продуктов, к которой относят вязкие и питьевые йогурты, пудинги, творожные массы, глазированные сырки, взбитые и мягкие творожки, коктейли и молочные муссы с различными наполнителями [4].

С целью повышения физиологической и пищевой ценности молочного мусса, а также для расширения его ассортиментного ряда используют различные способы и средства. В данном случае для его обогащения использовалось растительное сырье (рябина обыкновенная). Благодаря этому в продукте повышается содержание витаминов, аминокислот, минеральных веществ. Кроме того, рябина обыкновенная снабжает молочный мусс физиологически важными веществами, характерными только для растительного сырья.

Целью исследования является возможность производства молочного мусса с добавление джема из ягод рябины обыкновенной, который может стать популярным и недорогим десертом, пользующимся повышенным спросом потребителей [7].

Методика исследований. Новизна исследований заключается в разработке нового вида молочного десерта (мусса) с использованием рябины обыкновенной. В качестве плодовоягодного наполнителя выбран рябиновый джем. Данный вид молочного десерта будет обладать высокой пищевой ценностью, в нем будет содержаться большое количество витаминов, минеральных веществ и аминокислот за счет внесения наполнителя[2].

Таким образом, в качестве объектов исследования были изучены 3 образца молочного мусса с различным содержанием рябинового джема. Помимо опытных образцов производили исследования контрольного образца - мусса молочного:

образец 1 содержал 10 \% рябинового джема; образец 2 содержал 15 \% рябинового джема; образец 3 содержал 20 \% рябинового джема.
Результаты исследований. В результате были разработаны рецептуры молочного мусса с рябиной обыкновенной, представленные в табл. 1. Рецептуры отличаются между собой внесением наполнителя рябины обыкновенной.

Полученные образцы исследовали по органолептическим, физико-химическим показателям, также исследовали структуру каждого образца. У обьектов исследования определяли условия и сроки хранения. В результате опытных выработок была определена оптимальная доза внесения джема из ягод рябины. Органолептические показатели контрольного образца и образцов с внесеннием джема из ягод рябины представлены в табл. 2.

Контрольный образец имел однородную консистенцию, молочно-белый цвет и молочный, без посторонних примесей, вкус и запах.

Консистенция всех образцов была однородной, отсутствовали мучнистость и крупинки молочного жира и белка. Цвет образцов 1 и 2 был молочно-белым, слои джема не растекались и не опускались в слои молочного мусса. Образец 3 опустился в слой молочного мусса, тем самым нарушив консистенцию десерта. По вкусу и запаху образец 1 был приближен к контролю, рябиновый джем лишь в малой степени повлиял на вкусовые качества молочного мусса. В образце 2 с содержанием рябинового джема $15 \%$ преобладал наиболее приятный сладко-кислый вкус и слабо-выраженный запах рябины. Образец 3 имел сильновыраженный запах рябины и резкий кислый вкус с легкой горечью [1].

Балльная оценка органолептических свойств образцов молочного мусса с различным содержанием рябинового джема представлена на рис. 1.

Образцы исследовали по физико-химическим показателям, которые представлены в табл. 3.

Из приведенных в табл. 4 данных видно, что массовая доля жира и кислотность молочного мусса незначительно увеличиваются с повышением концентрации в нем джема из ягод рябины.

Массовая доля влаги контрольного образца молочного мусса была выше, чем влажность исследуемых образцов. Массовая доля влаги продукта уменьшалась с увеличением в нем концентрации рябинового джема.

Рецептуры молочного мусса

\begin{tabular}{|l|c|c|c|c|}
\hline \multicolumn{1}{|c|}{ Сырье } & Образец 1 & Образец 2 & Образец 3 & Контрольный образец \\
\hline Молоко, м.д.ж. 3,2\% & 658,8 & 647,7 & 609,6 & 762 \\
\hline Вода & 85,5 & 80,75 & 76,0 & 29 \\
\hline Желатин & 26,1 & 24,65 & 23,2 & 95 \\
\hline Сахар-песок & 85,5 & 80,75 & 76,0 & 19 \\
\hline Ванильный сахар & 17,1 & 16,15 & 15,2 & - \\
\hline Рябиновый джем & 100 & 150 & 200 & 1000 \\
\hline Итого & 1000 & 1000 & 1000 & \\
\hline
\end{tabular}


Органолептические показатели образцов молочного мусса с содержанием джема из ягод рябины

\begin{tabular}{|c|c|c|c|}
\hline \multirow{2}{*}{ Наименование образцов } & \multicolumn{3}{|c|}{ Характеристика показателей } \\
\hline & внешний вид и консистенция & цвет & вкус и запах \\
\hline Контрольный образец & $\begin{array}{c}\text { Поверхность глянцевитая, консис- } \\
\text { тенция нежная, однородная }\end{array}$ & Молочно-белый & $\begin{array}{c}\text { Чистые, в меру сладкие, } \\
\text { без посторонних вкусов } \\
\text { и запахов }\end{array}$ \\
\hline Образец 1 & $\begin{array}{c}\text { Поверхность глянцевитая, консис- } \\
\text { тенция нежная, однородная }\end{array}$ & $\begin{array}{c}\text { Молочно-белый, с } \\
\text { однородными слоя- } \\
\text { ми джема }\end{array}$ & $\begin{array}{c}\text { Молочно-рябиновый } \\
\text { сладкий вкус }\end{array}$ \\
\hline Образец 2 & $\begin{array}{c}\text { Поверхность глянцевитая, консис- } \\
\text { тенция нежная, однородная }\end{array}$ & $\begin{array}{c}\text { Молочно-белый, с } \\
\text { однородными слоя- } \\
\text { ми джема }\end{array}$ & $\begin{array}{c}\text { Слабовыраженный } \\
\text { запах рябины, сладко- } \\
\text { кислый вкус }\end{array}$ \\
\hline Образец 3 & $\begin{array}{c}\text { Поверхность глянцевитая, консис- } \\
\text { тенция нежная, однородная }\end{array}$ & $\begin{array}{c}\text { Молочно-белый, с } \\
\text { немного } \\
\text { неоднородными } \\
\text { слоями джема }\end{array}$ & $\begin{array}{c}\text { Ярковыраженный, } \\
\text { резкий, кислый вкус с } \\
\text { небольшой горечью }\end{array}$ \\
\hline
\end{tabular}

Таблица 3

Физико-химические показатели образцов молочного мусса с содержанием джема из ягод рябины

\begin{tabular}{|l|c|c|c|c|}
\hline \multirow{2}{*}{ Вид продукта } & \multicolumn{3}{|c|}{ Показатель } \\
\cline { 2 - 5 } & $\begin{array}{c}\text { массовая доля } \\
\text { жира, \% }\end{array}$ & $\begin{array}{c}\text { массовая доля } \\
\text { влаги, \% }\end{array}$ & $\begin{array}{c}\text { кислот- } \\
\text { ность, }{ }^{\circ} \mathrm{T}\end{array}$ & $\begin{array}{c}\text { плотность смеси } \\
\text { молочного мусса, кг/м }{ }^{3}\end{array}$ \\
\hline Контрольный образец & 3,6 & 80,01 & 18,00 & $1090 \pm 0,50$ \\
\hline Образец 1 & 3,7 & 75,48 & 18,00 & $1090 \pm 0,50$ \\
\hline Образец 2 & 3,75 & 71,66 & 18,00 & $1090 \pm 0,50$ \\
\hline Образец 3 & 3,8 & 66,52 & 19,00 & $1090 \pm 0,50$ \\
\hline
\end{tabular}

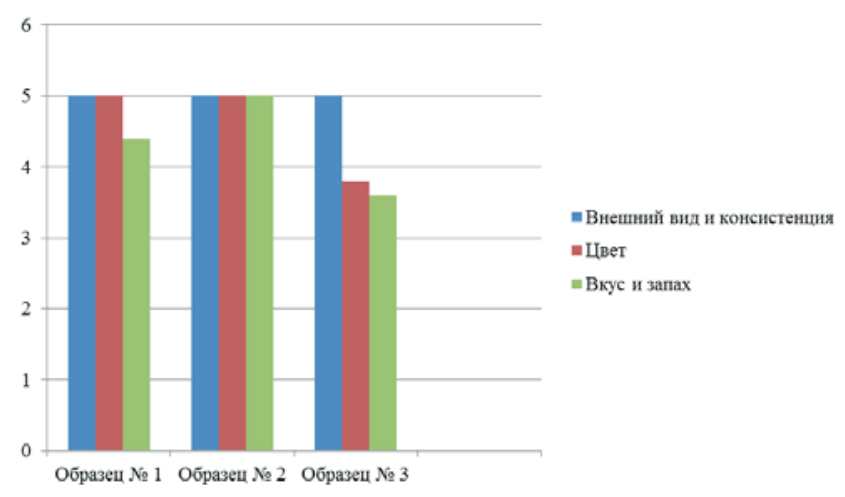

Рис. 1. Балльная оценка органолептических свойств образцов молочного мусса с различным содержанием джема из ягод рябины

Плотность во всех образцах продукции была примерно одинаковой, следовательно, введение джема из ягод рябины не изменяет плотности опытных образцов.

Во всех образцах была исследована взбитость молочного мусса. Результаты исследования контрольного образца и образцов молочного мусса с различным содержанием джема из ягод рябины на взбитость представлены в табл. 4.

Взбитость молочного мусса не изменяется с увеличением в нем концентрации джема из ягод рябины по отношению к контрольному образцу. Следовательно, введение в смесь рябинового джема не влияет на взбитость молочного мусса.

Наиболее оптимальным по концентрации джема из ягод рябины и органолептическим по- казателям образцом является образец 2. Внесение в молочный мусс именно такого количества джема из ягод рябины обогащает молочный продукт, в полной мере насыщает его вкусовые качества, не нарушая при этом консистенцию [6].

Цвет молочного мусса остается однородным по всей массе, слои джема из ягод рябины равномерны. Вкус и запах данного молочного десерта достаточно выраженный, нерезкий, приятный рябиновый.

Образец 1 по своим органолептическим свойствам в незначительной степени отличался от контрольного образца. Количество джема из ягод рябины, выбранного для этого образца, недостаточно насыщало продукт своими органолептическими свойствами. По физико-химическим свойствам образец 1 также был близок к физикохимическим свойствам контрольного образца.

В образце 3 наблюдалось ухудшение органолептических свойств по отношению к контрольному образцу. Цвет молочного мусса с содержанием рябинового джема в данном образце был неоднородным, из-за увеличения концентрации рябинового джем слои мусса опустились. Кроме того, запах данного образца был ярко выраженный рябиновый, а вкус резкий, кисло-горький. По физико-химическим показателям этот образец содержал наибольшую массовую долю жира и имел самую высокую кислотность.

Показатель взбитости у всех опытных об- 
нок контейнера. Механизм данного явления не

Показатель взбитости образцов молочного мусса с содержанием джема из ягод рябины

\begin{tabular}{|l|c|}
\hline \multicolumn{1}{|c|}{ Вид продукта } & Взбитость смеси, \% \\
\hline Контрольный образец & $41 \pm 0.30 *$ \\
\hline Образец 1 & $41 \pm 0,30 *$ \\
\hline Образец 2 & $41 \pm 0,30 *$ \\
\hline Образец 3 & $41 \pm 0,30 *$ \\
\hline \multicolumn{2}{|c|}{ * $<0,05$ - различия статистически достоверны. } \\
\hline
\end{tabular}

разцов не изменился по отношению к контрольному образцу [2].

По пищевой ценности полученные образцы молочного мусса обогащенного джема из ягод рябины имеют несомненные достоинства. Полученный рябиновый мусс безопасен по микробиологическим показателям. Добавление джема из ягод рябины в молочный мусс слоями позволяет полностью исключить внесение в молочный продукт дополнительных красителей.

Кроме того, молочный мусс после введения джема из ягод рябины приобретет легкий рябиновый привкус и аромат [8].

Исследования химического состава молочного мусса с добавлением джема из ягод рябины показали, что данный продукт является концентратом многих легко усваиваемых и дефицитных в питании человека компонентов [9].

Молочный мусс с рябиновым джемом рекомендуется реализовывать в короткие сроки для сохранения высокого качества продукта. Срок хранения при температуре $4 \pm 2{ }^{\circ} \mathrm{C}$ без значительных ее колебаниях выработанного молочного десерта без содержания джема из ягод рябины составляет 29 сут., молочного мусса с наполнителем - 25 сут.

При длительном хранении могут возникнуть многочисленные проблемы, каждая из которых может серьезно снизить качество продукта. Вследствиепотенциальных проблем наиболее важной является нарушение структуры молочного мусса из-за таяния желатина. Поскольку в молочный десерт не добавляются различные стабилизаторы консистенции, этого допускать нельзя [10].

Другая потенциальная проблема при хранении - это усадка молочного мусса. Она проявляется в том, что молочный мусс отходит от сте- вполне ясен, хотя этот дефект возникает наиболее часто при транспортировании молочного мусса между районами с различным атмосферным давлением. Изменения давления вызывают расширение и сжатие воздушных пузырьков, что в принципе может приводить к усадке [3].

В процессе хранения молочный мусс сравнительно легко воспринимает запахи из воздуха камеры, а также запахи тарно-упаковочных материалов. Может изменяться цвет молочного десерта [5].

Лишь при нарушении режимов и рекомендуемых сроков хранения может произойти химическое изменение жира, белков и других компонентов продукта, приводящее к возникновению серьезных пороков вкуса и запаха десерта. В процессе хранения молочного мусса с добавлением рябинового джема также изменяется кислотность (табл. 5).

На протяжении 30 сут. производили измерения кислотности в выработанном молочном муссе. В исследуемых образцах не наблюдалось нарастание кислотности интенсивней, чем в аналоговом продукте (рис. 2).

Срок годности исследуемых образцов с содержанием джема из ягод рябины составил 25 сут. В процессе хранения молочного мусса с джемом из ягод рябины меняются органолептические показатели (табл. 6).

На протяжении 30 сут. производили оценку органолептических показателей молочного мусса. Из приведенных данных видно, что при хранении молочного десерта органолептические показатели ухудшались по сравнению с контрольным образцом, что отрицательно влияло на срок годности выработанных видов молочного десерта.

По данным исследований разработаны рецептуры вырабатываемых видов молочного мусса (табл. 7).

Рецептура молочного мусса с содержанием $10 \%$ джема из ягод рябины представлена в табл. 8.

Рецептура молочного мусса с содержанием $15 \%$ джема из ягод рябины представлена в табл. 9.

Рецептура молочного мусса с содержанием $20 \%$ джема из ягод рябины представлена в табл. 10.

Таблица 5

Изменение кислотности в процессе образцов молочного мусса с содержанием джема из ягод рябины

\begin{tabular}{|l|c|c|c|c|c|}
\hline \multirow{2}{*}{ Вид продукта } & \multicolumn{5}{|c|}{ Изменение кислотности в процессе хранения, Т } \\
\cline { 2 - 6 } & $\begin{array}{c}\text { свежевыработан- } \\
\text { ный }\end{array}$ & $\begin{array}{c}\text { через 3 сут. } \\
\text { хранения }\end{array}$ & $\begin{array}{c}\text { через 10 сут. } \\
\text { хранения }\end{array}$ & $\begin{array}{c}\text { через 20 сут. } \\
\text { хранения }\end{array}$ & $\begin{array}{c}\text { через } 30 \text { сут. } \\
\text { хранения }\end{array}$ \\
\hline Контрольный образец & 18,0 & 18,0 & 18,2 & 19,0 & 20,0 \\
\hline Образец 1 & 18,0 & 18,0 & 18,5 & 19,2 & 20,1 \\
\hline Образец 2 & 18,0 & 18,1 & 18,8 & 19,5 & 20,5 \\
\hline Образец 3 & 19,0 & 19,0 & 19,4 & 20,0 & 20,9 \\
\hline
\end{tabular}


Балльная оценка изменения органолептических показателей в процессе хранения образцов молочного мусса с содержанием джема из ягод рябины

\begin{tabular}{|l|c|c|c|c|c|}
\hline \multirow{2}{*}{ Вид продукта } & \multicolumn{4}{|c|}{ Изменение органолептических показателей в процессе хранения, балл } \\
\cline { 2 - 6 } & $\begin{array}{c}\text { свежевырабо- } \\
\text { танный }\end{array}$ & $\begin{array}{c}\text { через 3 сут. } \\
\text { хранения }\end{array}$ & $\begin{array}{c}\text { через 10 сут. } \\
\text { хранения }\end{array}$ & $\begin{array}{c}\text { через 20 сут. } \\
\text { хранения }\end{array}$ & $\begin{array}{c}\text { через } 30 \text { сут. } \\
\text { хранения }\end{array}$ \\
\hline Контрольный образец & 5 & 5 & 4,7 & 4,4 & 4,2 \\
\hline Образец 1 & 5 & 5 & 4,7 & 4,4 & 4,2 \\
\hline Образец 2 & 5 & 5 & 4,7 & 4,2 & 4,0 \\
\hline Образец 3 & 5 & 5 & 4,6 & 4,1 & 3,9 \\
\hline
\end{tabular}

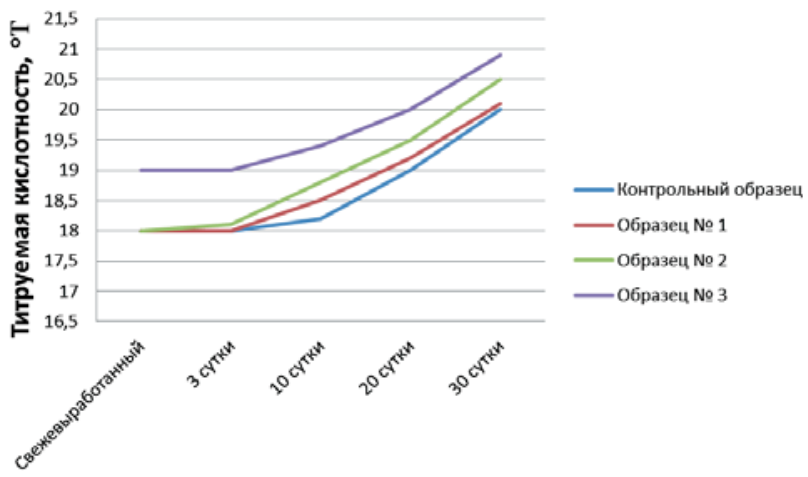

Рис. 2. Динамика кислотообразования в течение срока хранения

Таблица 7

Рецептура контрольного образца молочного мусса

\begin{tabular}{|l|c|}
\hline \multicolumn{1}{|c|}{ Сырье } & Количество, кг \\
\hline Молоко, м.д.Ж.3,2\% & 762 \\
\hline Вода & 95 \\
\hline Желатин & 29 \\
\hline Сахар-песок & 95 \\
\hline Ванильный сахар & 19 \\
\hline Рябиновый джем & - \\
\hline Итого & 1000 \\
\hline
\end{tabular}

Таблица 8

Рецептура молочного мусса с содержанием $10 \%$ джема из ягод рябины

\begin{tabular}{|l|c|}
\hline \multicolumn{1}{|c|}{ Сырье } & Количество, кг \\
\hline Молоко, м.д.ж. 3,2\% & 658,8 \\
\hline Вода & 85,5 \\
\hline Желатин & 26,1 \\
\hline Сахар-песок & 85,5 \\
\hline Ванильный сахар & 17,1 \\
\hline Рябиновый джем & 100 \\
\hline Итого & 1000 \\
\hline
\end{tabular}

Поскольку оптимальным по органолептическим и физико-химическим свойствам оказался образец 2, он был выбран для производства на предприятии. В табл. 11 представлены содержание минеральных веществ, витаминов, пищевая и энергетическая ценность в образце молочного мусса с содержанием джема из ягод рябины $15 \%$.

Заключение. По результатам исследований можно сделать следующие выводы:

1. Подобрано основное и вспомогательное сырье по ГОСТу (ГОСТ 31450-2013. Молоко питьевое, ГОСТ 21-94. Сахар-песок, ГОСТ 11293-89. Желатин, ГОСТ 16599-71. Ванильный сахар, ГОСТ 31712-2012. Джемы) и качеству, необходимым для
Таблица 9

Рецептура молочного мусса с содержанием $15 \%$ джема из ягод рябины

\begin{tabular}{|l|c|}
\hline \multicolumn{1}{|c|}{ Сырье } & Количество, кг \\
\hline Молоко, м.д.ж. 3,2\% & 647,7 \\
\hline Вода & 80,75 \\
\hline Желатин & 24,65 \\
\hline Сахар-песок & 80,75 \\
\hline Ванильный сахар & 16,15 \\
\hline Рябиновый джем & 150 \\
\hline Итого & 1000 \\
\hline
\end{tabular}

Таблица 10

Рецептура молочного мусса с содержанием $20 \%$ джема из ягод рябины

\begin{tabular}{|l|l|}
\hline \multicolumn{1}{|c|}{ Сырье } & \multicolumn{1}{c|}{ Количество, кг } \\
\hline Молоко, м.д.ж. 3,2 \% & 609,6 \\
\hline Вода & 76,0 \\
\hline Желатин & 23,2 \\
\hline Сахар-песок & 76,0 \\
\hline Ванильный сахар & 15,2 \\
\hline Рябиновый джем & 200 \\
\hline Итого & 1000 \\
\hline
\end{tabular}

производства молочного мусса. Основным сырьем является молоко сырое и джем из ягод рябины. Вспомогательным сырьем является сахар-песок, вода, желатин, ванильный сахар. В сырье исследовали массовую долю жира, массовую долю сухих веществ, плотность и кислотность. Все показатели соответствовали ГОСТам на сырье.

2. Разработана оптимальная рецептура молочного десерта с джемом из ягод рябины, содержание которого составляет $15 \%$.

3. В ходе проведения исследований были оценены органолептические показатели каждого вида молочного мусса с джема из ягод рябины: по вкусу и запаху: слабовыраженный запах рябины, сладко-кислый вкус, по внешнему виду и консистенции: поверхность глянцевитая, консистенция нежная, однородная, по цвету: молочно-белый с однородными слоями джема.

4. По физико-химическим показателям измеряли: массовую долю жира (3,75 \%), массовую долю влаги $(71,66 \%)$, кислотность $\left(18^{\circ} \mathrm{T}\right)$ и

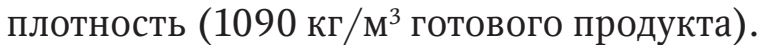

5. Разработаны технологические режимы 
Пищевая и энергетическая ценность контрольного образца и образца с содержанием $15 \%$ джема из ягод рябины

\begin{tabular}{|l|c|c|}
\hline \multicolumn{1}{|c|}{ Показатель } & Контрольный образец & Образец 2 \\
\hline Массовая доля сухих веществ, \% & 19,9 & 28,3 \\
\hline Массовая доля влаги, \% & 80,1 & 71,7 \\
\hline Массовая доля жира, \% & 2,45 & 2,11 \\
\hline Массовая доля углеводов, \% & 13,36 & 13,08 \\
\hline Массовая доля белка, \% & 4,66 & 4,02 \\
\hline Витамин А, мг & 0,18 & 1,53 \\
\hline Витамин С, мг & 13,72 & 14,21 \\
\hline Кальций, мг & 111,74 & 97,83 \\
\hline Калий, мг & 118,11 & 134,91 \\
\hline Магний, мг & 9,91 & 26,71 \\
\hline Фосфор, мг & 83,82 & 85,17 \\
\hline Взбитость, \% & $41 \pm 0,30^{*}$ & $41 \pm 0,30^{*}$ \\
\hline Титруемая кислотность, ${ }^{\circ}$ Т & 18,0 & 18,0 \\
\hline Энергетическая ценность, КДж & 94,13 & 87,39 \\
\hline
\end{tabular}

производства молочного десерта с рябиновым джемом. Для производства нового вида продукта используется двухступенчатый режим гомогенизации и температура пастеризации $85{ }^{\circ} \mathrm{C}$ с выдержкой 50-60 с. Это способствует повышению взбиваемости смеси, улучшению консистенции готового молочного мусса, придает ему нежность, предотвращает появление мучнистости. Высокие режимы тепловой обработки обьясняются тем, что оказывают защитное действие на микроорганизмы.

6. Установлены сроки хранения молочного мусса с рябиновым джемом. Срок хранения молочного мусса с рябиновым джемом составил 25 сут. при температуре $4 \pm 2{ }^{\circ} \mathrm{C}$, так как спустя 25 сут. органолептические показатели изменяются: наблюдается выделение сыворотки, расслоение продукта, по вкусу ощущается горечь и кислый привкус, кислотность составляет $20,5^{\circ} \mathrm{T}$, что влияет на качество продукта.

Выпуск таких молочных продуктов частично решит проблемы экономии сырьевых молочных ресурсов, использования такого ценного сырья, как рябина обыкновенная и одновременно расширит ассортимент конкурентоспособных функциональных продуктов.

\section{СПИСОК ЛИТЕРАТУРЫ}

1. Бескова Н.А., Мамаев А.В., Сергеева Е.Ю., Инновационный подход в технологии домашнего сыра с использованием растительного сырья // Современные тенденции развития науки и производства: материалы III Междунар. науч.-практ. конф. - Донецк, 2016. - С. $165-167$.

2. Бобракова Л.А., Мамаев А.В., Родина Н.Д. Исследование реологических параметров при производстве обогащенного зерненого творога // Вестник Бурятс- кой государственной сельскохозяйственной академии им. В.Р. Филиппова. - 2016 -№ 2 (43). - С. 101-106.

3. Болкунов П.С., Мамаев А.В., Родина Н.Д. Новое мороженое с биологически активным комплексом spirulina PLATENSIS // Материалы Междунар. науч.практ. конф. студентов, аспирантов и молодых ученых. Евразийский союз ученых. - 2014. - № 8-10. - С. 73.

4. Болкунов П.С., Родина Н.Д., Куприна А.О. Физико-химические характеристики и сохранность нового мороженого с $1 \%$-м с содержанием SPIRULINA PLATENSIS // Материалы Междунар. науч.-практ. конф. студентов, аспирантов и молодых ученых. Национальная Ассоциация Ученых. - 2015 - № 4-5. C. $145-146$.

5. Болкунов П.С., Мамаев А.В., Родина Н.Д. Влияние концентрации spirulina platensis на изменение специфических показателей мороженого // Материалы Междунар. науч.-практ. конф. студентов, аспирантов и молодых ученых. Международный научный институт «Educatio». - 2015 - № 3-8. - С. 52-53.

6. Болкунов П.С., Мамаев А.В., Родина Н.Д. Научная новизна и практическая значимость применения мороженого с биологически активным комплексом «СПИРУЛИНА-Л"Н» // Материалы Междунар. науч.практ. конф. студентов, аспирантов и молодых ученых. Евразийский союз ученых. - 2016. - № 3-3(24). C. 14-16.

7. Василевская Е.Б., Мамаев Е.Ю., Сергеева Н.Д. Влияние морской капусты на сроки хранения сметаны // Фундаментальные и прикладные исследования - сельскохозяйственному производству: материалы VIII Междунар. науч.-практ. Интернет-конференции. - 2016. C. $145-149$.

8. Васильева Д.А., Родина Н.Д., Мамаев А.В. Стевия как заменитель сахара в технологии плавленых сыров // Использование современных технологий в сельском хозяйстве и пищевой промышленности: материалы Междунар. науч.-практ. конф. студентов, аспирантов и молодых ученых. - 2016. - С. 130-134.

9 Изотов В.В., Сергеева Е.Ю., Родина Н.Д. Исполь- 
зование ягодно-овощных соков в технологии молочного пудинга // Современные тенденции развития науки и производства: материалы III Междунар. науч.-практ. конф. - Донецк, 2016. - С. 167-169.

10. Келдибекова Д.А., Мамаев А.В. Перспективы применения пектина при разработке кисельного молочного продукта с сорбционными свойствами // Актуальные проблемы науки XXI века: III Междунар. конф. - 2015. - С. 6-9.

Меркулова Анастасия Андреевна, магистрант, Орловский государственный аграрный университет имени Н.В. Парахина. Россия.

Родина Наталья Дмитриевна, канд. биол. наук, доцент кафедры «Продукты питания животного происхождения», Орловский государственный аграрный университет имени Н.В. Парахина. Россия.

Сергеева Екатерина Юрьевна, канд. техн. наук, до- иент кафедры «Продукты питания животного происхождения», Орловский государственный аграрный университет имени Н.В. Парахина. Россия.

Мамаев Андрей Валентинович, $\partial-p$ биол. наук, проф. кафедры «Продукты питания животного происхождения», Орловский государственный аграрный университет имени Н.В. Парахина. Россия.

Цикин Сергей Сергеевич, канд. техн. наук, доцент кафедры «Продукты питания животного происхождения», Орловский государственный аграрный университет имени Н.В. Парахина. Россия.

302019, г. Орел, ул. Генерала Родина, 69.

Тел.: (4862) 76-15-17.

Ключевые слова: молочный мусс; джем; рябина обыкновенная; органолептические показатели, кислотность; образцы молочного мусса.

\title{
DEVELOPMENT AND EVALUATION OF QUALITY INDICATORS OF MILK MOUSSE WITH A FILLER - SORBUS
} AUCUPARIA

Merkulova Anastasiya Andreevna, Magistrandt, Orel State Agrarian University named after N.V. Parakhin. Russia.

Rodina Natalya Dmitrievna, Candidate of Biological Sciences, Associate Professor of the chair "Food of Animal Origin", Orel State Agrarian University named after N.V. Parakhin. Russia.

Sergeeva Ekaterina Yurievna, Candidate of Technical Sciences, Associate Professor of the chair "Food of Animal Origin", Orel State Agrarian University named after N.V. Parakhin. Russia.

Mamaev Andrey Valentinovich, Doctor of Biological Sciences, Professor of the chair "Food of Animal Origin", Orel State Agrarian University named after N.V. Parakhin. Russia.

Tsikin Sergey Sergeevich, . Candidate of Technical Sciences,
Associate Professor of the chair "Food of Animal Origin", Orel State Agrarian University named after N.V. Parakhin. Russia.

Key words: dairy mousse, jam; Sorbus aucuparia; organoleptic indicators; acidity, samples of milk mousse.

The authors developed the recipe of a few samples of milk mousse with filler-jam from the berries of Sorbus aucuparia. All samples were tested by organoleptic and physical and chemical parameters. Increase in acidity was observed; scoring indicators of milk mousse with jam from berries of Sorbus aucuparia was produced.

\section{ЭКСПЕРИМЕНТАЛЬНОЕ ИССЛЕДОВАНИЕ МОЩНОСТИ ДЛЯ ПРИВОДА ПНЕВМОВИНТОВОЙ УСТАНОВКИ ПРИ ТРАНСПОРТИРОВАНИИ ЗЕРНА}

УдК 631.861

\author{
ПАВЛОВ Павел Иванович, Саратовский государственный аграрный университет имени \\ Н.И. Вавилова
}

КОРСАК Виктор Владиславович, Саратовский государственный аграрный университет имени Н.И. Вавилова

ОВЧИННИКОВА Татьяна Владимировна, Саратовский государственный аграрный университет имени Н.И. Вавилова

В статъе изложены методика и результаты экспериментальных исследований мощности для привода пневмовинтовой установки при транспортировании зерна. Указаны приборы и способы задавания и замера основных параметров. Представлены уравнения регрессии и графические зависимости влияния скорости осевого воздушного потока, частоты вращения и шага шнека. Установлены значения указанных параметров, при которых мощность, необхоимая для привода, имеет минимальное и максимальное значение.

Введение. Пневмовинтовая установка применяется для транспортирования зерна на зерноскладах, хранилищах, элеваторах. Благодаря одновременному воздействию на зерно шнека и потока воздуха в пневмовинтовой установке достигается более высокая производительность в сравнении со шнековым транспортером [2, 3, 5-8, 10]. Другим важным параметром оценки работы является мощность, необходимая для привода рабочих органов. Суммарная мощность $\mathrm{P}_{\Sigma}$, Вт, для транспортирования зерна пневмовинтовой установкой включает в себя мощность, необходимую для привода шнека, и мощность для привода вентилятора, создающего воздушный поток $[2,4]$. 